\title{
CORROSION MONITORING OF GALVANIZED STEEL IN SIMULATED WET-DRY CYCLIC CONDITION IN 0.05 M NACL SOLUTION
}

\author{
A.P. Yadav* \\ *Central Department of Chemistry, Tribhuvan University, Kirtipir, Kathmandu, Nepal.
}

\begin{abstract}
The corrosion monitoring of galvanized steel in $1 \mathrm{~h}$ wet and $7 \mathrm{~h}$ dry cyclic condition in $0.05 \mathrm{M} \mathrm{NaCl}$ has been carried out using AC impedance technique. During the wet-dry cycles, the polarization resistance, $R_{\mathrm{p}}$, and solution resistance, $R_{\mathrm{s}}$, were continuously monitored. The instantaneous corrosion rate of the coating was estimated from the obtained $R_{\mathrm{p}}^{-1}$ and time of wetness (TOW) was determined from the $R_{\mathrm{s}}$ values. The corrosion potential, $E_{\text {corr }}$, was measured twice a day during the immersion period of wet-dry cycle. The corrosion was accelerated by the wet-dry cycles in the early stage followed by a decrease in the final stage of wet-dry cycle. The corrosion potential shifted to more negative direction for the first 8 cycles due to dissolution of air formed oxide. A gradual shift in the corrosion potential with the progress of corrosion in the later stage of the wet-dry cycle was observed due to deposition of corrosion products. The corrosion mechanism of galvanized steel is discussed based on the results of corrosion monitoring and corrosion potential variation.
\end{abstract}

Key words: Atmospheric corrosion; Galvanized steel; AC Impedance; Corrosion rate.

\section{INTRODUCTION}

The galvanized steels are used in a variety of applications, such as bridges, buildings, and automobiles. In most of these applications, these steels are exposed in atmosphere, where it weathers in wet and dry cyclic conditions due to variation in temperature and humidity in day and night. Corrosion process in atmospheric environments is very different from that in the bulk solutions because corrosion proceeds under a thin electrolyte layer during periodic wet and dry cycle. Under thin electrolyte layer, the diffusion of oxygen is greatly enhanced ${ }^{1,2}$. But, the solvation capacity of a thin electrolyte layer for the dissolved species becomes very limited, which affects the process of formation and transformation of corrosion products ${ }^{3}$. The corrosion proceeds at negligibly small rate under water molecule layers. In the presence of moisture, which is easily saturated with oxygen from the atmosphere, the cathodic reaction (either oxygen reduction or hydrogen evolution) is not rate controlling step. The corrosion rate in such a situation is controlled by anodic reaction. In the wet condition, an increase in the thickness of electrolyte layer decreases the corrosion rate, which is controlled by diffusion process. ${ }^{2}$ Highest corrosion rate is attained in transition from moist (anodic control) to wet corrosion (cathodic control). The critical thickness of electrolyte layer for maximum corrosion rate has been estimated to be approximately $20-30 \mu \mathrm{m}^{1,2,4}$.
The surface of galvanized steel becomes wet at a relative humidity below $100 \%$. Because of the presence of hygroscopic impurities in the air or in the metal itself, the critical humidity for condensation to occur is usually much lower than $100 \%$. It has been reported that nighttime corrosion is about three times more than daytime corrosion due to high humidity during the night ${ }^{5}$.

With the increasing demand of galvanized steel, more knowledge regarding the behavior of galvanized steel corrosion in atmospheric environment is needed. There are several studies on the atmospheric corrosion of galvanized steel using conventional methods ${ }^{6,7}$, which takes very long time. Electrochemical study on the galvanized steel corrosion in sodium sulfate medium has been extensively studied ${ }^{8-10}$. However, electrochemical study on galvanized steel corrosion in sodium chloride medium is limited ${ }^{11-14}$. The electrochemical data on the effect of periodic wet and dry conditions on the time to red rust and the coating life of galvanized steel are desirable.

In this study, Electrochemical Impedance spectroscopy (EIS), which has proved to be quite useful technique for monitoring of the atmospheric corrosion ${ }^{15,16}$, was used to monitor the corrosion rate of galvanized steel under a wet-dry cyclic condition. The purpose was to evaluate the corrosion

Author for Correspondence: A.P. Yadav, Central Department of Chemistry, Tribhuvan University, Kirtipir, Kathmandu, Nepal. Email: amar2y@yahoo.com. 
behavior of galvanized steel corroding under wet-dry cyclic condition in $0.05 \mathrm{M} \mathrm{NaCl}$ solution at $298 \mathrm{~K}$.

\section{EXPERIMENTAL}

\section{Cell design and its set-up}

A two-electrode cell configuration with the exposed area of $1 \mathrm{~cm}^{2}$ each, as shown in Fig. 1, was used as a probe for the corrosion monitoring. A commercial hot dip galvanized steel sheet with the coating thickness of $18-20 \mu \mathrm{m}\left(135 \mathrm{gm} / \mathrm{m}^{2}\right.$ on one side) was used as the probe electrode. A pair of identical electrodes was cut into the dimension of $14 \times 14 \times 2.5 \mathrm{~mm}$ from the galvanized steel sheet and cleaned by sonicating with acetone for 2 minutes. One side of the metal plate was connected to the lead wire using silver paste. The connection of the plate and wire was covered by quick drying epoxy after 20 min to make sure that the connection was secured. The two plates were then mounted in an ambient temperature solidifying epoxy resin with the separation gap of $0.1 \mathrm{~mm}$. In order to avoid crevice corrosion on the exposed area and on the edges separating the two metal sheets, these were covered with a thin layer of epoxy resign. The experimental cell thus prepared was set on an acrylic vessel placed inside a temperature and humidity controlled chamber. The cell was set with its metal surface facing upwards and a water leveler was used to ensure that the cell was placed horizontally.

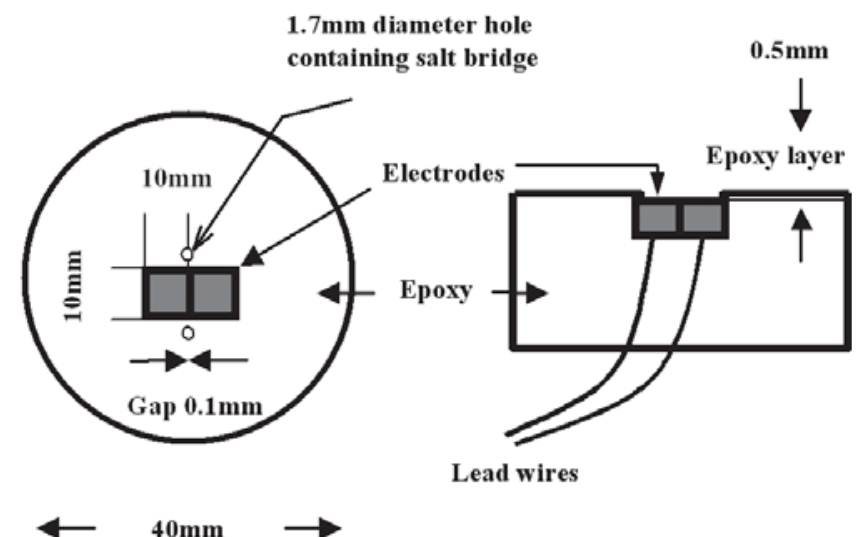

(a)

(b)

Fig. 1: Schematic diagram of two electrode cells used for monitoring of impedance and corrosion potential (a) Top view (b) Transverse cross-sectional view.

A three-electrode cell configuration was employed for polarization measurement with an $\mathrm{Ag} / \mathrm{AgCl}, \mathrm{KCl}$ (sat) reference electrode (SSE) and a $\mathrm{Pt}$ sheet as a counter electrode.

\section{Wet-dry cyclic set-up}

The wet-dry cyclic test is an excellent way of evaluating the performance of coated materials in a simulated atmospheric environment. The wet-dry cycle test was conducted in a laboratory chamber by exposing the sample to alternate conditions of $1 \mathrm{~h}$-immersion in a $0.05 \mathrm{M} \mathrm{NaCl}$ solution and 7 h drying at $298 \mathrm{~K}$ and $60 \% \mathrm{RH}$. It is noteworthy that at $60 \%$ $\mathrm{RH} \mathrm{NaCl}$ crystal has little water absorbing capacity so that during the drying period the probe surface can be kept almost dry. The test solution was introduced into the acrylic vessel from an external storage tank through the inflow magnetic valve programmed to deliver enough volume to submerge the test specimen for $1 \mathrm{~h}$. The test solution was then drained through the out flow magnetic valve and the cell was left to dry at $298 \mathrm{~K}$ and $60 \% \mathrm{RH}$. To ensure the constancy of electrolyte layer thickness at the onset of each dry cycle, a peripheral bank of $0.5 \mathrm{~mm}$ thick was fixed on the electrode surface. This gave a layer thickness of about $0.5 \mathrm{~mm}$ on the initiation of the dry period. The cyclic test was done for 14 days comprising 42 cycles. The detail of cyclic wet-dry setup has been described elsewhere ${ }^{17}$.

The test solution was prepared from analytical grade $\mathrm{NaCl}$ in double distilled water. Triplicate samples were exposed to check the reproducibility of the data.

\section{Corrosion monitoring by AC impedance}

Continuous monitoring of corrosion of the galvanized steel was performed by using an AC corrosion monitor (RIKEN DENSHI CT-3) with a multiplexer controlled by a personal computer. Special software was used for data acquisition at the time interval of $12 \mathrm{~min}$. This system operates at two frequencies, high frequency, $10 \mathrm{kHz}\left(Z_{\mathrm{H}}\right)$ and low frequency, $10 \mathrm{mHz}\left(Z_{\mathrm{L}}\right)$. The impedances were simultaneously measured at these frequencies, and the polarization resistance, $R_{\mathrm{p}}$, was determined by subtracting the high frequency impedance from the low frequency one as follows:

$R_{\mathrm{p}}=\mathrm{Z}_{\mathrm{L}}-\mathrm{Z}_{\mathrm{H}}$

This is based on the assumption that the high frequency impedance gives the solution resistance and the low frequency provides a sum of solution resistance and polarization resistance.

The corrosion current density, $i_{\text {corr }}$ can be calculated from the measured $R_{\mathrm{p}}$ value by using Stern-Geary equation [18] given by

$i_{\text {corr }}=k R_{\mathrm{p}}^{-1}$,

where $k$ is a proportional constant and is given by the expression

$k=1 / 2.303\left(b_{\mathrm{a}} b_{\mathrm{c}} / b_{\mathrm{a}}+b_{\mathrm{c}}\right)$,

Here $b_{\mathrm{a}}$ and $b_{\mathrm{c}}$ are the anodic and cathodic Tafel slopes for zinc dissolution and oxygen reduction, respectively.

The average corrosion mass loss, $\Delta M\left(\mathrm{~g} \mathrm{~cm}^{-2}\right)$ of zinc coating after the exposure periods of $t(\mathrm{~s})$ was calculated by using the relation as follows:

$\Delta M=\left(M_{\mathrm{Zn}} / 2 \mathrm{~F}\right) \int_{0}^{\mathrm{t}} i_{\text {corr }} \mathrm{dt}$

where $M_{\mathrm{Zn}}$ is atomic weight of zinc $\left(=65.4 \mathrm{~g} \mathrm{~mol}^{-1}\right)$, and $\mathrm{F}$ is Faraday constant $\left(=96485 \mathrm{C} \mathrm{mol}^{-1}\right)$. Average coating thickness loss, $\Delta T$ was calculated by dividing $\Delta M$ value by the density of zinc $\left(7.14 \mathrm{~g} \mathrm{~cm}^{-3}\right)$.

During the corrosion monitoring, corrosion potential was measured twice a day during the last period of $1 \mathrm{~h}$ immersion. 
One of the two metal plates of the probe was used as the working electrode while the other one was used as the counter electrode. The reference was a saturated silver-silver chloride electrode.

\section{RESULTS AND DISCUSSION}

\section{Corrosion monitoring under wet-dry cycles}

The wet and dry cyclic test was carried out by exposure to alternate conditions of $1 \mathrm{~h}$-immersion in a $0.05 \mathrm{M} \mathrm{NaCl}$ solution and drying at $25^{\circ} \mathrm{C}$ and $60 \% \mathrm{RH}$ for $7 \mathrm{~h}$. During the wet-dry cycles, continuous monitoring of corrosion and the solution conductance of the corroding probe were measured every 12 min. The reciprocal of polarization resistance $\left(R_{\mathrm{p}}^{-1}\right)$ was taken as an index of the corrosion rate and the solution conductance $\left(R_{\mathrm{s}}^{-1}\right)$ was used to calculate the time of wetness (TOW). The results of the corrosion monitoring $\left(R_{\mathrm{p}}^{-1}\right)$ and corresponding solution conductance are shown in Fig.2 and Fig.3, respectively. The general trend of corrosion was that it accelerated in the early stage up to $120 \mathrm{~h}$ and then gradually decreased in the later stage. The visual observation of the corroded surface showed that the corrosion products were thick and porous and the corrosion attack was heterogeneous. No red rust could be observed with naked eyes at the end of exposure test.

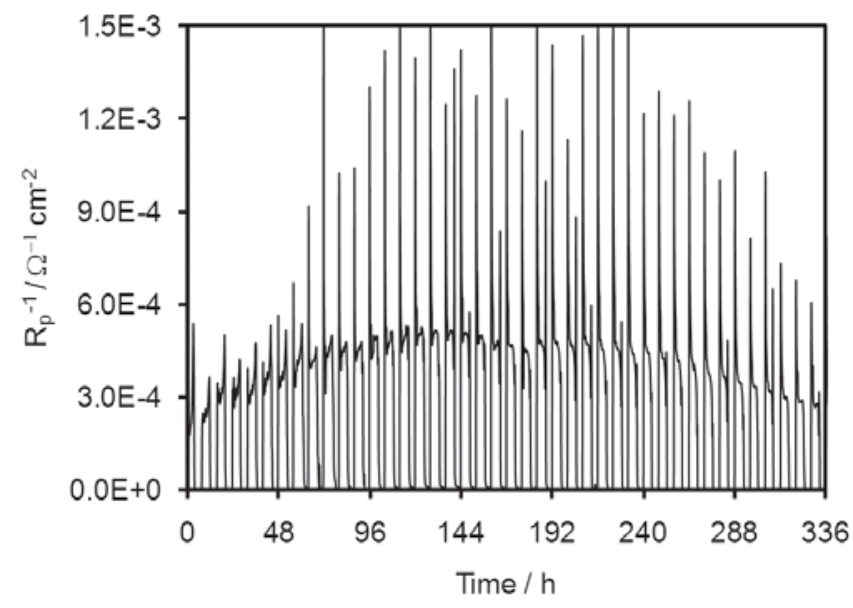

Fig. 2: Corrosion monitoring results of galvanized steel under $1 \mathrm{~h}$ immersion and $7 \mathrm{~h}$ drying in $0.05 \mathrm{M} \mathrm{NaCl}$ solution at $298 \mathrm{~K}$ and $60 \% \mathrm{RH}$.

To better understand the corrosion process, a plot of $R_{\mathrm{p}}^{-1}$ and $R_{\mathrm{s}}^{-1}$ of a single wet-dry cycle against time is made in Fig.4. The variation of $R_{\mathrm{p}}^{-1}$ reveals that within each cycle, it increased sharply just after the probe was submerged in the test solution (an increase in solution conductance), and just before the probe surface dried up in the early stages of drying. During the onset of wet cycle, early stage of region $\mathrm{I}, R_{\mathrm{p}}^{-1}$ is relatively small indicating that the metal surface was passive at the end of preceding dry cycle. The initially higher value of solution conductance (region I) at the onset of wet period (Fig.4) compared to the latter part of the wet-dry cycle can be attributed to the initially high concentration of chloride ions at the electrode surface due to dissolution of $\mathrm{NaCl}$ crystal, which precipitated during the drying period of the preceding wet-dry cycle. The removal of bulk solution and the onset of

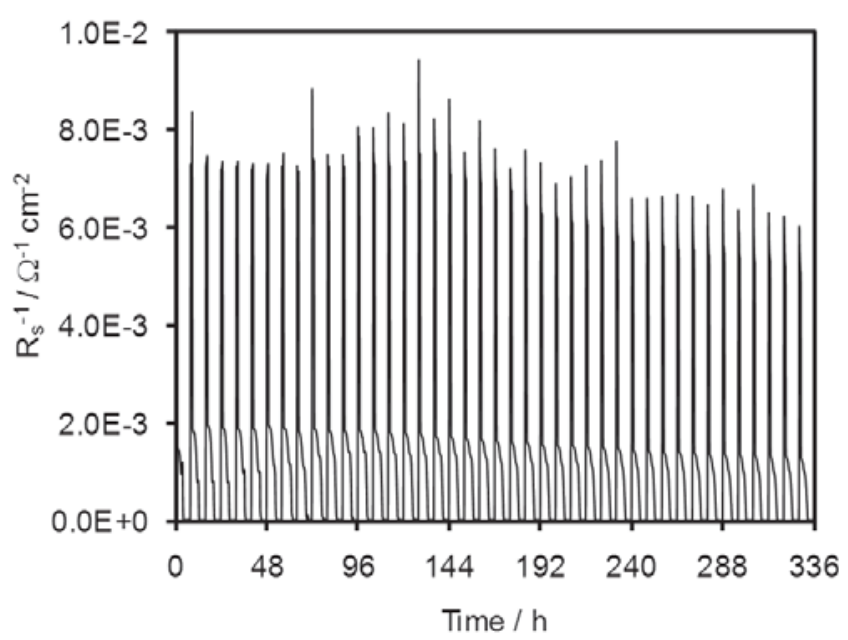

Fig. 3: Monitoring results of reciprocal of solution resistance obtained from the high frequency impedance at $10 \mathrm{Khz}$ under $7 \mathrm{~h}$ drying condition.

drying are reflected on the sudden decrease in the solution conductance (region II). The sudden decrease in solution conductance was due to the uneven current distribution over the working electrode under thin electrolyte layer. During the initial period of region II, the corrosion rate still maintains a low value. However, as drying progressed, the corrosion rate started to increase rapidly, including a peak at the latter part of the drying. Afterwards, it decreased suddenly before it dropped to an almost very low, but non-zero, solution conductance (region III in Fig.4). The rapid increase of $R_{\mathrm{p}}^{-1}$ observed in region II was due to the increasing aggressively of the environment as a result of increased chloride concentration and an increase in the rate of mass transport through the thin electrolyte layer as drying progresses.

The sudden decrease in the $\mathrm{R}_{\mathrm{p}}^{-1}$ after it peaked does not necessarily reflect repassivation, but it may be attributed to the inhibition of mass transport of dissolved species due to thinning of electrolyte layer. This thin electrolyte layer saturates with dissolved species and hence decrease the

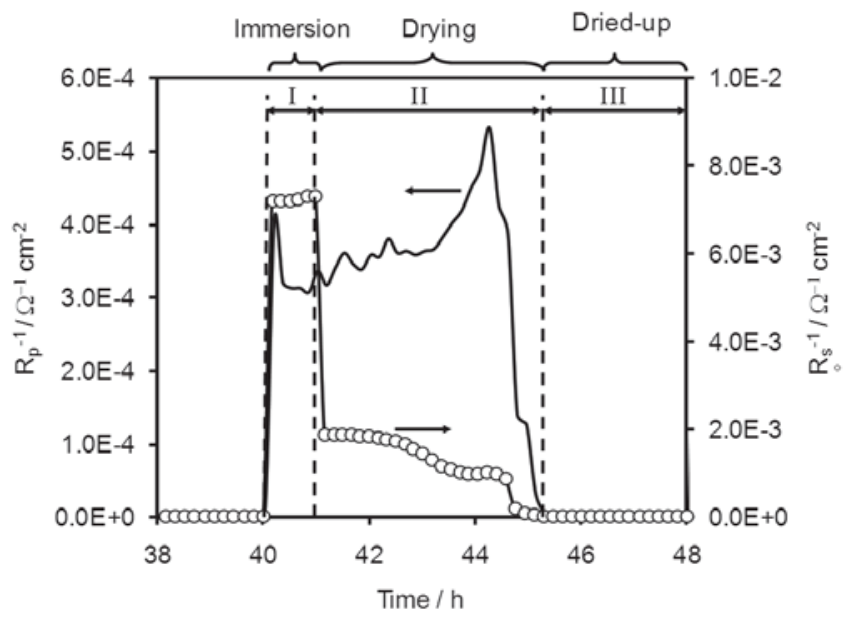

Fig. 4: Monitoring results of one wet-dry cycle showing plots of $R_{\mathrm{p}}^{-1}$ and $R_{\mathrm{s}}^{-1}$ in the initial stage. Solid line represents $R_{\mathrm{p}}^{-1}$ value while open circle represents $R_{\mathrm{s}}^{-1}$ value. 


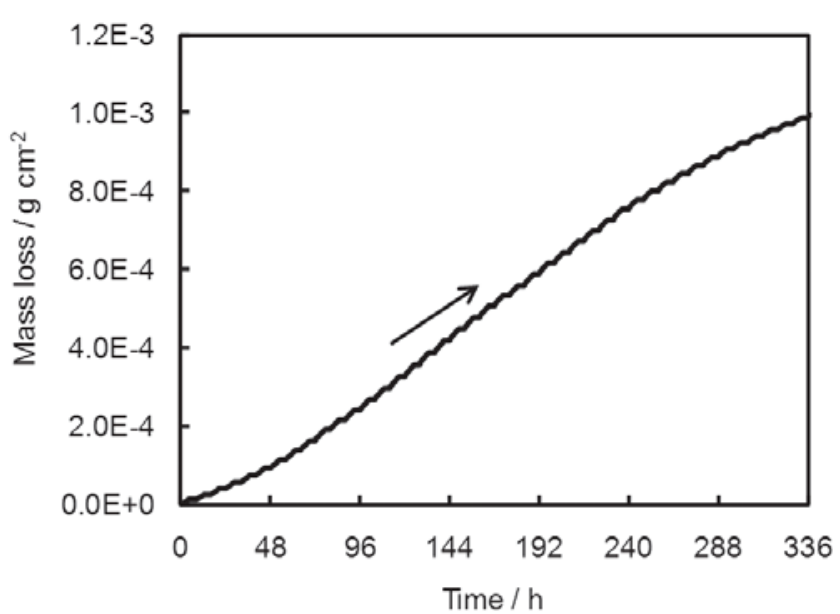

Fig. 5: Corrosion mass loss of galvanized steel obtained from integrating the $R_{\mathrm{p}}^{-1}$ vs time curves of Fig. 2 .

solubility of oxygen ${ }^{1,4}$. Drying proceeds further until the surface dries out and salt crystal remain on the surface (region III).

\section{Time of wetness}

The corrosion rate averaged over whole exposure time (336 h) is often used to evaluate the coating performance. However, as the corrosion proceeds at negligibly small rates when the surface is completely dried up, it is better to consider an average corrosion rate when the sample surface is covered with a conductive electrolyte layer. This will give better understanding of the influence of drying or wet periods on the corrosion process. The time of wetness has been defined as the total time during which the relative humidity is higher than the critical value of condensation. Guttman and Sereda ${ }^{19}$ have determined the critical humidity as $86 \%$, where the zinc surface remains wet.

In this study, the time of wetness (TOW) was determined from the solution conductance versus time plot in Fig. 3. The solution conductance was found to vary from $2.0-7.0 \times 10^{-3} \Omega$ ${ }^{1} \mathrm{~cm}^{-2}$ during 1 h-immersion and it dropped to $0.8-1.0 \times 10^{-4} \Omega^{-1}$ $\mathrm{cm}^{-2}$ on the onset of drying period and slowly decreased to almost zero when the surface dried up completely. Therefore, TOW can be taken as the time periods when the solution conductance is greater than $1 \times 10^{-4} \Omega^{-1} \mathrm{~cm}^{-2}$. The TOW was estimated to be $193 \mathrm{~h}$ which corresponds to about $57 \%$ wet of the total exposure period $(336 \mathrm{~h})$.

\section{Average corrosion rate}

To estimate the average corrosion rate, $I_{\text {avr }}$, over whole exposure time, the $R_{\mathrm{p}}^{-1}$ vs. time curves in Fig. 2 were integrated and the integrated values were divided by the total exposure time (336 h), i.e.

$I_{\mathrm{avr}}=\frac{k}{336} \int_{0}^{336} R_{\mathrm{p}}^{-1} \mathrm{dt}$

On the other hand, the average corrosion rate $I_{\text {avr }}^{*}$, over time of wetness (TOW) was estimated by dividing the integrated values by TOW, i.e.
$I_{\text {avr }}^{*}=\frac{k}{\mathrm{TOW}} \int_{0}^{336} R_{\mathrm{p}}^{-1} \mathrm{dt}$

The $k$ value was set at $0.015 \mathrm{mV}$ for initial stage, $0.01 \mathrm{mV}$ until $48 \mathrm{~h}$ of exposure and $0.05 \mathrm{mV}$ after $48 \mathrm{~h}$ exposure ${ }^{14}$. The average corrosion rate, $I_{\mathrm{avr}}$, during the total exposure period $(336 \mathrm{~h})$ was estimated to be about $4.0 \times 10^{-6} \mathrm{~A} \mathrm{~cm}^{-2}$. On the other hand, the average corrosion rate during time period when the surface was wet, $I_{\text {avr }}^{*}$, was estimated to be about $7.1 \times 10^{-6} \mathrm{~A} \mathrm{~cm}^{-2}$.

The average mass loss $(\Delta M)_{\text {total }}$ of the coating layer was calculated from Eq. (4) and is shown in Fig.5. The average mass loss increased with the increase of exposure time showing that the environment for corrosion was aggressive and that a protective corrosion product was not formed. The average thickness loss of the coating layer was estimated at $1.4 \mathrm{~mm}$, which was less than $10 \%$ of the coating thickness.

\section{Corrosion potential}

Corrosion potential is a mixed potential at which the rate of anodic dissolution of the metal equals the rate of cathodic reactions and there is no net currents flowing in and out of the metal. Any changes in conditions, such as surface state, concentration, $\mathrm{pH}$, aeration, etc., that affect the anodic and cathodic reactions will affect the value of the corrosion potential. A change in the corrosion potential in either anodic or the cathodic direction may lead to a decrease or an increase in the corrosion rate.

In this work, corrosion potential, $E_{\text {corr }}$, was measured twice a day only during $1 \mathrm{~h}$ immersion condition. The result is shown in Fig. 6. In the initial stage the corrosion potential lies in the vicinity of equilibrium potential of zinc. This is primarily due to the high exchange current density for zinc dissolution and relatively much smaller exchange current density for the cathodic reactions on zinc.

For first few cycles the $E_{\text {corr }}$ shifted to less noble values due to enhancement of anodic dissolution of the coatings ${ }^{13}$. As the cycle progressed, the corrosion products were deposited on the surface and the potential gradually shifted in noble direction. The corrosion potential at the end of $336 \mathrm{~h}$ exposusre

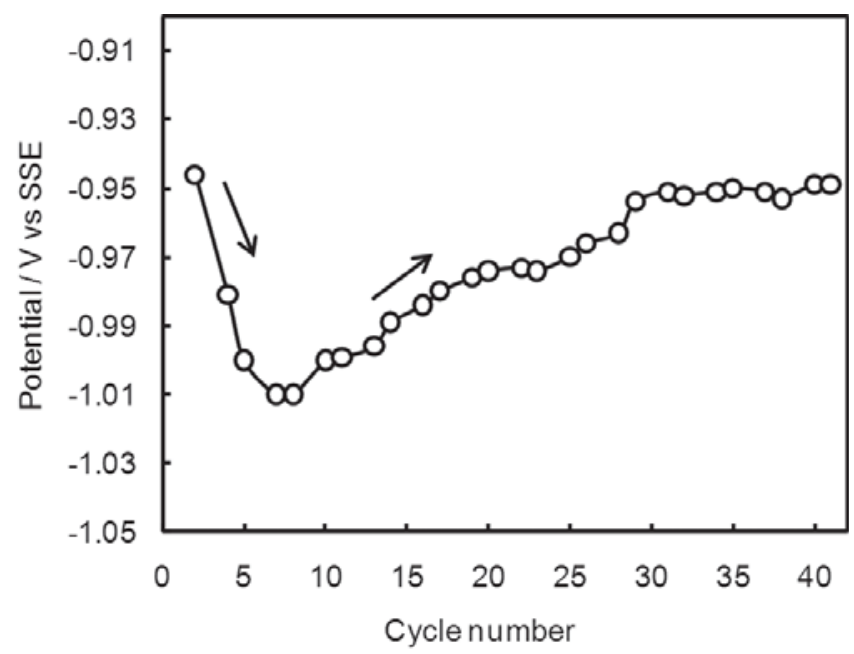

Fig. 6: Time variation of corrosion potential measured during immersion period of wet-dry cycle twice a day. 
was about $-0.950 \mathrm{~V}$. This range of potential is sufficiently negative than potentials needed for cathodic protection of ordinary steels, $\sim-0.77 \mathrm{~V}$, where it is expected that the zinc coating layer around a defect would act as a sacrificial anode $^{12}$.

\section{Polarization behavior}

The polarization behavior of zinc coating layer in $0.05 \mathrm{M} \mathrm{NaCl}$ solution is shown in Fig. 7. The current-potential curve was measured at a scan rate of $1 \mathrm{mV} / \mathrm{s}$ from the open circuit potential towards either anodic or the cathodic direction at $25^{\circ} \mathrm{C}$, using as polished samples. Before start of the measurement, sample was kept in $0.05 \mathrm{M} \mathrm{NaCl}$ solution for 30 min. Accordingly, its surface was considered to be covered with a very thin oxide layer of zinc. A diffusion limiting current of oxygen reduction can be seen in the early stage of cathodic polarization. However, at lower potentials (less than $-1.5 \mathrm{~V}$ ), the reduction of $\mathrm{H}_{2} \mathrm{O}$ becomes more dominant, leading to a progressive increase in the current density. The Tafel slope of the anodic polarization curve, $b$, was estimated to be about $0.035 \mathrm{~V} /$ decade, which is in general agreement with the reported value ${ }^{13}$. On the other hand, the Tafel slope of the cathodic side, $b$, was determined to be infinite $(\infty)$, assuming that the oxygen reduction rate is controlled by diffusion process.

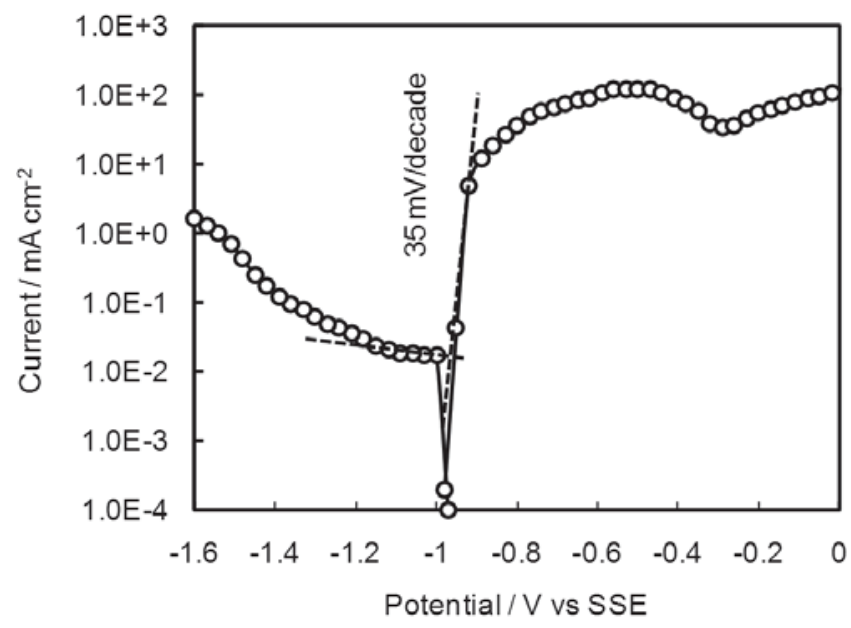

Fig. 7: Polarization curve of galvanized steel measured in $0.05 \mathrm{M}$ $\mathrm{NaCl}$ solution at scan rate of $1 \mathrm{mV} / \mathrm{s}$ after immersion for $30 \mathrm{~min}$.

From the results of monitoring data and corrosion potential, corrosion mechanism under wet-dry cyclic environment can be proposed. A gradual increase of corrosion rate in the early stage of wet-dry cycle accompanied by a shift in the $E_{\text {corr }}$ towards more negative values indicate the acceleration of anodic dissolution of coating layer. This is probably due to the removal of air formed surface oxide film. After $8^{\text {th }}$ cycle, the corrosion rate continued to increase but the $E_{\text {corr }}$ shifted towards noble direction due to formation of thick white rust.

\section{CONCLUSIONS}

From the results of monitoring data and corrosion potential of galvanized steel, the following conclusions are made:

1. The corrosion monitoring by using AC impedance method is a quick way of evaluating the performance of coating layer in wet-dry cyclic condition.

2. The corrosion rate of galvanized coating under $1 \mathrm{~h}$ wet and $7 \mathrm{~h}$ dry cyclic condition showed an initial increase followed by gradual decrease. During whole wet-dry cyclic test no red rust was observed with naked eyes.

3. The corrosion potential shifted to negative value in the early stage of wet-dry cyclic test due to dissolution of air formed oxide. With the formation of porous corrosion products the $\mathrm{E}_{\text {corr }}$ took a noble value.

\section{REFERENCES}

1. Nishikata, A., Ichihara, Y., Hayashi, Y., Tsuru, T. 1997. J. Electrochem. Soc. 114: 1244.

2. Tomashov, N. D. 1964. Corrosion 20: 76.

3. Stiles, D. C., Edney, E. O. 1967. Corrosion 23: 15.

4. Stratmann, M., Streckel, H. 1990. Corros. Sci. 30: 697.

5. Dey, A.K., Sinha Mahapatra, A.K., Khan, D.K., Mukharjee, A.N., Narain, R., Mukharjee, K.P., Banerjee, T. 1966. In Interim report on atmospheric corrosion studies under marine atmosphere, Tech. J. 8: 11.

6. Haynie, F.H., Spence, J.W., Lipfert, F.W., Cramer, S.D., McDonald, L.G. 1990. In Evaluation of an atmospheric damage function for galvanized steel, ASTM STP 1000: 225.

7. Spence, J.W., Haynie, F.H., Lipfert, F.W., Cramer, S.D., McDonald, L.G. 1992. Corrosion 48: 1009.

8. Cachet, C., Ganne, F., Maurin, G., Petitjean, J., Vivier, V., Wiart, R. 2001. Electrochim. Acta, 47: 509.

9. Cachet, C., Ganne, F., Joiret, S., Maurin, G., Petitjean, J., Vivier, V., Wiart, R. 2002. Electrochim. Acta, 47: 3409.

10. Sziraki, I., Cziraki A., Gerocs, I., Vertesy, Z., Kiss, L. 1998. Electrochim. Acta, 43: 175.

11. Katayama, H., Tay, Y.C., Viloria, A.S., Nishikata, A. and Tsuru, T. 1998. Material Transaction JIM 38: 1089.

12. Yadav, A.P., Nishikata, A., Tsuru, T. 2004. Corros. Sci. 46: 361.

13. Yadav, A.P., Nishikata, A., Tsuru, T. 2004. Corros. Sci. 46: 169.

14. Yadav, A.P., Suzuki, F., Nishikata, A., Tsuru, T. 2004. Electrochmi. Acta. 49: 2725.

15. Nishikata, A., Ichihara, Y., Tsuru, T. 1995. Corros. Sci. 37: 897.

16. Nishikata, A., Ichihara, Y., Tsuru, T. 1996. Electrochim. Acta. 41: 1057.

17. Nishikata, A., Yamashita, Y., Katayama, H., Tsuru, T., Usami A., Tanabe, K., Mabuchi, H. 1995. Corros. Sci. 37: 2059.

18. Stern, M., Geary, A. L. 1957. J. Electrochem. Soc. 104: 56.

19. Guttman, H., Sereda, P.J. 1968. Measurement of atmospheric factors affecting the corrosion of metals, ASTM STP 435: 326. 